\title{
A POÉTICA CABOCLA NOS TEXTOS DE VEREQUETE: INDÍCIOS DE UMA OBRA FEITA PARA O CANTO.
}

\section{Marcos André CUNHA \\ Universidade Federal do Pará}

\begin{abstract}
Resumo: Trabalhamos a função poética como um aspecto que aponta para ima performance cantada dos textos de Verequete (compositor paraense). O processo metafórico aparece enquanto determinante da função poética, ressaltando o predominio do lirismo no texto do artista investigado. $O$ estudo da função poética é realizado baseado en Jakobson (lingïista da Escola de Praga) e na retórica dássica.
\end{abstract}

Conforme se produza um texto para ser lido ou para ser falado (ou cantado), neste texto deverá haver qualidades intrínsecas que 'denunciam' a finalidade e a situação cm que deverá ser lido ou ouvido. l'ara Dupont (1994, p.14/16):

A instituição literária instaura um contrato social entre o scriptor ansente e seu leitor, contrato que, exclusivamente, da acesso ao texto. Esse contrato está inscrito dentro do kexto $c^{\prime}$ possibilita que o texto lido não seja a mensagem de ningı́m para qualquer un. A retórica de um texto (...) impōe, ‘om efeito, um tipo de enunciação muito particular precxisurnte...

Num texto já há marcas que de certa forma prevếen os interlocutores (leitores/ouvintes), as situaçes de proficriço do mesmo. Năo se trabalhará o código da mesma mancira quando se quiser passar uma notícia por meio de um texto on quandes se quiser prochuzir um texto para ser cantado, ou mesmo quando o vécule da noticia for $\mathbf{1 m}$ jornal escrito ou televisionado. No cases de una notícia, o fiece tende a ser a informação que se queira transmitir; jí no casos do texto para serr cantado, é provável que se atente bem mais para os próprios significantes, ou seja, para o som das palavras (ritmo, aliterações, linha melódica, etc..), pois a ênfase no significantc caracteriza a funçāo poética. Buscando encontrar nos textos de Verequete indícios que os 
a.utrizem como sendo produzidos visando o canto, investigareme I inciéncia da função poética no compositor.

No estudo da função poética, nos embasamos na abordagem de Jikubson (1988, p.130): "A função poética projeta o princípio d " ‘uivalência do eixo da seleçāo sobre o eixo da combinação." A tẹ deste autor exposta acima é que, nos textos em que predomina a funçli puética da linguagem, as palavras são selecionadas não somente poi apresentarem relações de sentido que favorecem sua combinaçĭo fit sintagma', mas também por manifestarem uma semelhança entre significantes. Esta semelhança que caracteriza o cixo paradigmático (on cixo da seleção) aparece então no eixo sintagmático (ou eixo combinação). Quando, na construção do discurso, se ressalta o cixo scleçẫo (paradigma), o que caracteriza o predomínio da função poétiẹ há uma ênfase para o que Jakobson chama processo metafórico.

\section{O PROCESSO METAFÓRICO NOS TEXTOS DI VEREQUETE $^{2}$}

Jakobson (1988) ressalta sobre o processo metafórico:

A poesia visa ao signo (...) O princípio de similaridade domiini a poesia; o paralelismo métrico dos versos ou a equivalentin fônica das rimas impōem o problema da similinde $\mathrm{e}$ a contraste semânticos (...)

Mais importante no texto em que predomina a função poética lin ć o fato de se referir a algo (funçāo referencial), mas sim de dar ênfi para a própria mensagem. As palavras são selecionadas em fuṇ̣ também de seus significantes, de modo que no eixo da contigüidade preserve a similaridade própria do eixo paradigmático. $\mathrm{O}$ cixo da seleçi se torna o elemento organizador do sintagma.

Cabe aqui um esclarecimento sobre os termos e os conceitos metáfora e de metonímia. Sabe-se que Jakobson chama 'proceik metafórico' a combinação de palavras (eixo sintagmático) qui

\footnotetext{
1 () sintagma é utilizado aqui como sinônimo de oração, pressupondo relação subordintît

(O) textos aqui investigados constituem o corpus utilizado cm nossa pesquisa de mestrado, 1 ) "1 cariter semántico da pesquisa, o que demanda a necessidade de se cstudar detalladament thalulate de cada texto, sclecionamos uma quantidade menor de textos do total de trinta Au cunpus para verificarmos a funçăo poética. Investigaremos dez textos do compositof
} 
A1"uscutam semelhanças (sonoras ou gráficas, portanto, no cixu |'u.ıligmuático); esta projeçāo de um eixo sobre o outro caractcriza a (1114,io poética, pois contribui para dar ênfase para a própria mensagem 11.4 sua materialidade. Ora, a abundância de figuras retóricas ( 1 'uncipalmente, metáforas e metonímias, desta vez no sentido clássico), I'+t chamar a atenção para a mensagem em si, como qualquer efeito 'sético, também contribui para a função poética. Isto faz com que 1.1110 metáforas como metonímias, no sentido da retórica clássica, sejam l.ıtres da função poética, ou seja, elementos do processo metafórico in. sentido de Jakobson.

Da relação entre o 'processo metafórico' e as metáforas e uctonímias no sentido clássico são tiradas duas conseqüências para asc estudo:

1) Ao investigar a função poética, portanto, o 'processo metafórico' no sentido de Jakobson, no nosso corpus, se procurará também o que a tradição retórica chama de metáfora e metonímia.

2) Para evitar toda a ambigüidade, as palavras metáfora e metonímia ( e scus derivados) serāo aqui explicitamente referidas à retórica, toda vez que não remeterem à teoria de Jakobson.

Conforme Platão e Fiorin (1994, p.122) será metáfora (retórica): "A alteração do sentido de uma palavra ou expressāo quando entre o sentido que o termo tem e o que ele adquire existe uma interseç̧̄o"

Os autores consideram intersecção o fato de haver traços semânticos comuns entre duas palavras, ou melhor, entre o sentido que duas palavras apresentam. Em: "A urbanização de São Paulo está sendo feita de mancira criminosa, porque está destruindo os pulmōes da cidade (op. cit., p. 122)." Viu-se a expressão 'pulmōes da cidade' substituinclo a palavra 'árvores' pelo fato do significado da palavra 'pulmão' c 'árvore' apresentar um traço comum: a função de oxigenar. Para os mesmos autores, será metonímia: "A alteração do sentido de uma palavra ou expressĩ̄o quando entre o sentido que o termo tem e o que alepuire existe uma relaçōo de inclusão ou de implicação (op. cit. , p.123)."

A inclusão diz respeito ao fato de $u$ m sentido estar cm outro, conter outro; já a implicação também apresenta um sentido relativo comum à inclusão, significa algo que está pressuposto $\mathrm{cm}$ algo, que é conseqüente (Ferreira, 1986, p. 923/931). Em: "As chaminés deveriam ir para fora da cidade de São Paulo. ( Platão \& Fiorin,1994, p.123)." A palavra 'chaminé' está substituindo a palavra 'fábrica' pelo fato daquela estar inclusa nesta. Assim, 'chaminé' é metonímia de 'fábrica'.

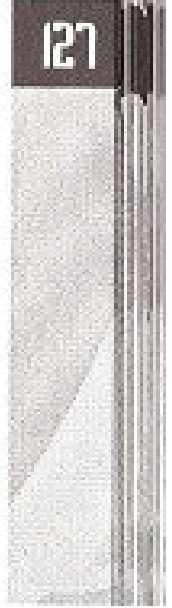


lintiı, 'a projeçāo do princípio de equivalência do cixo da seleçlí subre a cixo da combinação' poderá ser mais ou menos realçad ‘unfurne haja relaçāo semântica (metáfora ou metonímia no sentide rctrico e sinonímia e antonímia) mais ou menos estreita entre a palavras co-presentes no sintagma. Considerando estas relaçōes, uso de figuras retóricas tende a reforçar mais ainda a função poétiẹ $1111 \mathrm{n}$ texto.

No intuito de se investigar não somente o predomínio da funçi poćtica como também a maneira como ela se manifesta nos textos d Verequete, se verificará se por meio das equivalências ou combinaçố sonoras ${ }^{3}$, se constroem ou se realçam relaçōes semânticas mais menos estreitas, bem como metáforas e metonímias retórica, ou sel se investigará até que ponto é enfatizado o processo metafórico ne textos do compositor.

Os ciez textos analisados do compositor estão divididos em du categorias:

A- Textos em que há equivalência fồnica entre palavras sem relaçố semânticas estreitas;

B- Textos em que há equivalência fônica entre palavras com relậlit scmântica estreita.

Serāo consideradas relaçōes semânticas próximas, as que caracterizam pela sinonímia e antonímia ou produzem metífora! metonímias retóricas. Entre os textos que apresentam relaçé semânticas estreitas há duas subcategorias:

B.1 Textos em que há equivalência fônica entre palavras com relaęô semânticas estreitas;

B.2 Textos em que há equivalência fônica entre figuras retóri (metáforas e metonímias)

\footnotetext{
1. usada a equivalência sonora, expressăo utilizada por Jakobson (ver infra, f. 12\%), pafl referirmos às rimas $\mathrm{c}$ assonâncias. Quando as relaçōes sonoras năo forem rimas nem assonilnt chamaremos de combinação sonora.

+ Segundo Dubois et alii (1997, p. 555) há duas acepçóses para sinonimia: são sinỏnimos dois fẹt substituivcis num único enunciado isolado; quando sāo intercambiáveis $\mathrm{cm}$ todos os contekcu "1 primciro conceito que utilizamos. , A coincidéncia entre os traços definitórios permite que pralavra substitua outra, dependendo do contexto. Este permite que se de às unidades un sein Inıstante restrito. Quanto à antonímia, conforme o mesmo autor, "sāo unidades de sentidos conlt hi wsa nuқ̧ ás de contrírio define-se $\mathrm{cm}$ geral em relaçio a termos vizinhos, os complement (uus lks vs, fenca) e os recíprocos (vender vs. comprar) ${ }^{\circ}$. (op. cit, p. 56). Consideraremos sineili prat ias para as palavras que apresentam traços semãnticos comuns.
} 


\section{2. () processo metafórico nos textos de Verequete}

1 in todos os textos de Verequete, presentes no corpus deste II ilı,llw, há a presença, com maior ou menor freqüência, de rimas c Anuruluncias. A presença destas combinaçōes fônicas sāo indícios Mịnulu .tivos da predominância da função poética porque as rimas c Amanincia são elementos do mesmo paradigma que se encontram Bumburulos no sintagma. Veja-se a incidência de cada categoria:

A - Texto em que há equivalência fônica entre palavras sem relaçöes semânticas estreitas: Somente um foi encontrado V.18 ( $2^{\circ}$ estrofe):
$\ddot{o}$ valei- mi nossa senhora vóis mi queira mi ajuDA carimbó uirapuru tá boTANdu pra queBRA..

A vung̣al central $/ \mathrm{a} / \mathrm{faz}$ a correspondência sonora entre os três últimos Veisur. desta estrofe. Tal vogal constrói uma combinaçāo sonora entre as GHFi.' verbais infinitivas 'ajuDA' e 'queBRA'. Na palavra 'uirapuru' o hiêpu tu dá ĉnfase à vogal central (em negrito) verificando-se o deslocamento) d0 in + 11 s tônico desta palavra. Somente a palavra 'Nossa Senhora' não sc'

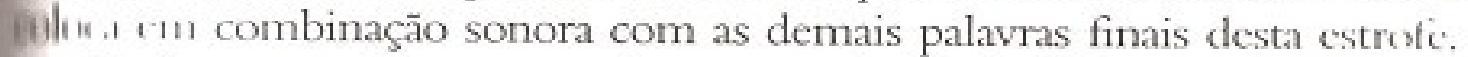

lunbıra se tenha encontrado certa equivalência fônica entre as palavrass thais aks versos desta estrofe, não foram encontradas relaçōes sinônimas,

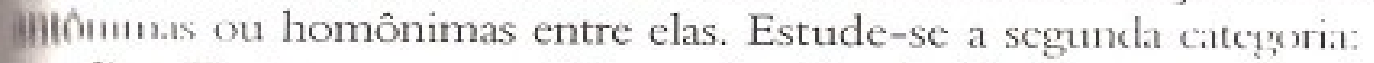

1" - Textos em que há equivalência fônica entre palavras com relação semântica estreita.

11.1 - Textos em que há equivalência fônica entre palavras com relaçôes sinônimas totais ou parciais: $\mathrm{Al}_{\mathrm{g}}$ uns exemplos podem ser vistos. Em V.12:

\section{a casinha du caBOcu \\ é tacada di taboca \\ na bera di um riAchu \\ cober:ta cum sororoca}

$\Lambda$ cưuivalência fônica é observada entre os substantivess 'caBOcu', Іарен i' " 'sororoca'. A maior semelhança sonora verifica-se entre as 
Aluas riltimas palavras. Estas se encontram quase em relação sinônim liis pralavras se referem a espécies vegetais utilizadas como matéria prima para construção da habitação do caboclo.

Esta proximidade semântica entre 'taboca' e 'sororoca' se realẹ pelo fato de que, no interior dos significantes de tais signos lingüístice se encontra outro signo, no caso, o substantivo 'oca'. A 'oca' \& uil sinônimo que, ao mesmo tempo em que denomina um objeto, qualifica, pois nāo é qualquer tipo de casa e sim a 'casinha du caBOẹt Assim, nas mesmas palavras que denominam a matéria-prima utilizad para a construção da 'casinha do caBOcu' se encontra outra palavra qu funciona como sinônimo desta habitação.

Considerando os substantivos 'taboca' e 'sororoca' em relaçấa oca, pode-se verificar uma relação metonímica retórica. Assim, 'taboca' e a 'sororoca' estão na casa. Constituem-se numa parte da 'oẹ da 'casinha du caBOcu'.

Na segunda estrofe ${ }^{5}$, o espaço de moradia do caboclo ganha relevi Este demonstra a satisfação com sua morada, com seu estilo de vida
caBOcu toca viola
caBOcu bati tam BO:
caBOcu só acha bom
moRANdu num interiO:

Apesar de não ser estreita a relação semântica entre as palavras qui rimam 'tamBO' e 'interiO', esta estrofe está incluída nesta categoì por apresentar uma combinação sonora que reforça o sentido da primeil estrofe, pois no primeiro verso o verbo 'toca', além de se combinai sonoramente com a palavra 'tacada' da primeira estrofe, ainda reali internamente o substantivo principal do texto: a 'oca'.

Também em V.20 ( $3^{\circ}$ texto) se verifica a 'oca' podendo interpretada como sinônimo de 'tapiri":

\section{faZENdu men tapiri \\ cum isteiu di taboca \\ nessa DOci samambaia \\ converSA cum sororoca}

\footnotetext{
Nessi estrofe tal como $\mathrm{cm}$ V.18 as relaçōes significativas cntre as palavras que rimam nlle wevitas. Nessa porćm, a relaçāo de sentido é mais evidente, pois as duas palavras que rimith
w referem ao mesmo stujeito.
} 
(1) mesmo sentimento de satisfação por parte do nativo da An.1/unia constatado em V.12 é expresso nesta estrofe. Novamente I11. intrior dos signos lingüísticos 'taboca' e 'sororoca' verifica-sc a fial.13.1 'oca', que pode ser considerada sinônimo do 'tapiri'. Este ć um Iij... "k construção improvisada que serve como pousada: (Assis, 1992, 1 lis.) lugar em que o caboclo se acolhe quando está em sua lida, em Hi1. atividades extrativistas. Ressalte-se ainda a combinação fônica entre 17. 'ulsitintivos 'tapiri' e 'taboca', pois sāo duas palavras de três sílabas, fii1 t.11klo por uma sílaba comum /ta/. Na solidão da lida o caboclo torna h1111.1110 o ser vegetal fazendo dele seu interlocutor 'conversa cum munua'. Verifica-se uma prosopopéia ${ }^{6}$. Em V.18:

\section{O pau cain tiniu \\ Lá nu MAtu ninguéin vin}

I ssa estrofe inicia o texto e funciona como refrão repetindo-se Yâı. vezes. O ditongo estabelece a equivalência fônica entre as sílabas Ulia lon mas verbais que rimam ('tiniu' e 'caiu') encerrando os dois versos. EII11 . palavras 'tiniu' e 'viu' verifica-se uma estreita relação semântica pelı l.11 das duas formas verbais referirem-se à percepção sensorial. A p.ılıtalização da consoante / $t$ dental no significante 'tiniu' pode EN|"r.s. o estrondo que ecoa do 'pau'

As rclações semânticas se estreitam mais quando se analisa csta filluls cm relação à segunda, em que se fala do carimbó ${ }^{7}$. Assim, o 'pan' prule ser entendido como a metáfora do 'carimbó'. O instrumentos 'liminu' com que se realiza o som é feito de um tronco de irvore, un beja, ck. um 'pau'. Isto ratifica a metáfora.. Assim, o som do 'cirimbu घirapuru' cooa ao longe. Ainda que não se veja, não se esteji presente para sc ver 'o carimbó', se é contagiado anditivanente pelo nuesmos.

P'nencem também a esta categoria de textos: V.07 (2" estrofe), Vi0 ( $2^{\circ}$ estrofe) e V.10 ( $1^{\circ}$ estrofe)

\subsection{Textos em que há equivalência fônica entre palavras ên relaçốes metafóricas e metonímicas:}

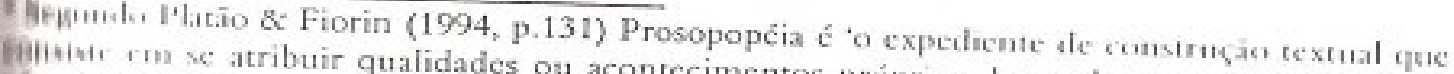
19. lumuans".

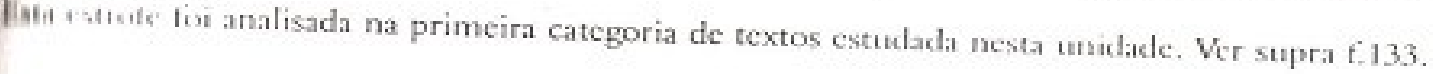

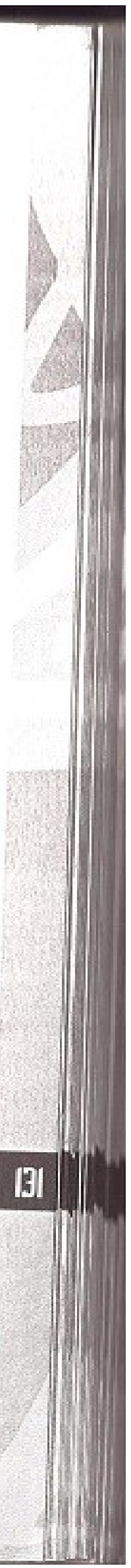


Primeiramentc observen-sc as metonimias retóricas. Vejamse dois exumplos. Em Vo7 ( 1 estrofic):

\author{
Ce vo pre gapó \\ to tiRA cipó \\ verin cá morchinha \\ vein dank 1 u carimbó
}

Verifica-se a cquivalência fonice entre os substantivus oxitonos 'gapú' c. 'वips. O primciro denomina um lusat que é propicio ì existència do

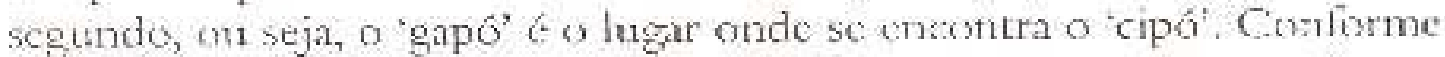
Ferreira $(1986$, p.835) 'gapó' ć uma variate de "igapo", refere-sc à "mata dieia de água". Fstas palavras tambem se combinam sonuratrente com o subst.milive final da cstrufe carmb5: Conforme Leal (1908, p.10) esta

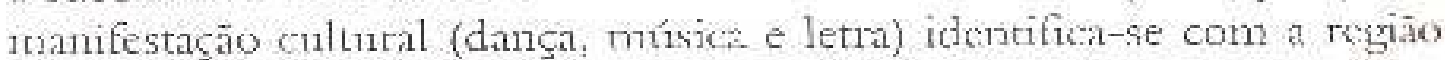
do Salıgado paracnse: Tsiti regiăo é propícia ì existência do 'grậ́, Assim, no texto, interage o 'carimió, genuino da rejziāo, com o espaço físico natural que a caractefiza. O espaç que figurativiza a rotina cabocla e revelado jela açầ que se: exerce no ambinate (o gapó onde se tira o (ipos). A rotina do trabalho cm contimuidade com o momento do lazer é caracteríscica ramberm do caboclo.

Veja-se agora a primeira parte di: V.20 (1' cstrofic):

$$
\begin{aligned}
& \text { Elá é lá e lá } \\
& \text { a haiO jha du NOsen Pará } \\
& \text { a ilha do Marajó } \\
& \text { tén GRAN lili povtuaçáu } \\
& \text { aONidi nascent "I carimbó } \\
& \text { mu TTMMn da iscravidau }
\end{aligned}
$$

Nesta estrote vemos a cquivalência fônica rcialçando três metonímas retóricas, $\mathrm{O}$ adverbio lấ rima cuth o substantivo 'Pará'. A 'illa' e um tugar do 'Pará'. Estat estrofe exalta um ícone do cstado do

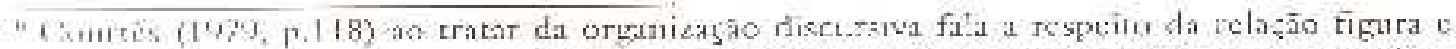

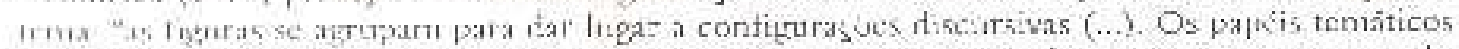

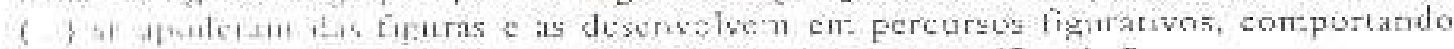

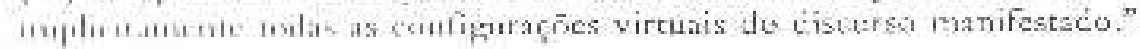




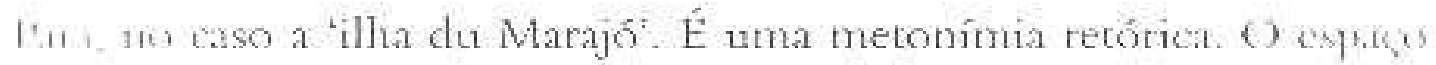

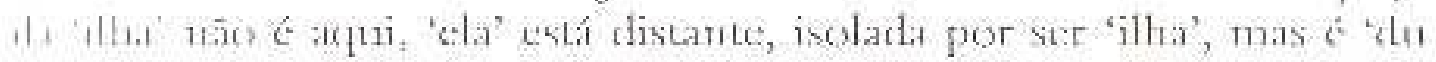
I I 1.su l'ara'. Entrc os substantivos "Marajo" c 'carimbó há outra

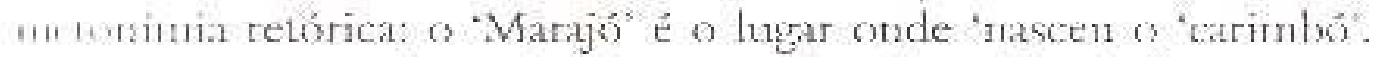

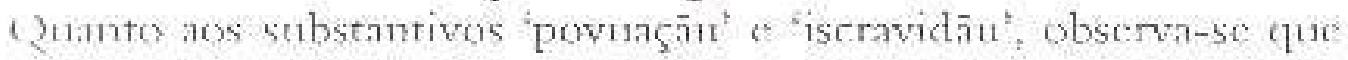
a winivalêria sonora verificada entre a silaba final desces realç uma

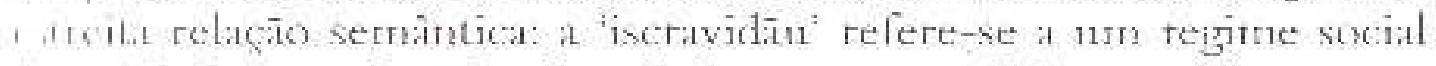
li sugççio se exploração do trabalho, como também se retere a uma wndiçăo social imposta ao povo (Ferreira, 1989, p. 220). Apesar de "11 11 toxho o povo ter sido escravizuto, nảo se pode negar que a maioria

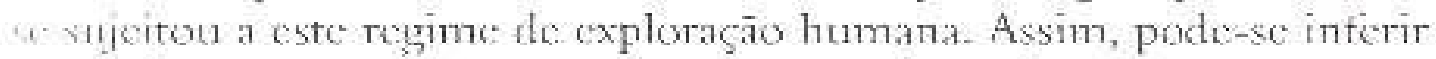
inia relaça metonimica retórica entre os doss subsamcivos.

Pode-se interit una relaçio sinonínica entre a expressấs é lá do princiro versa com is expressīo 'maiO ilha' do segundo verso. A cpetiçấo por várıs vezes do primciro verso 'E lît, constituido pelo

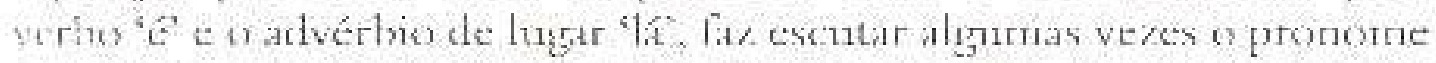
reso de terceira pessoa 'cla', ainda que a accntuaçāo desra palavra co das inceroces sejan diferentes.

Finte o scegudo e o terceiro wersos existe um saso especial de wietornimia retórica, denominado anconomásia , ou seja, a característica gue methor indixiduatiza os substantixo a majo ilha din NOssu Pará (cxpressa no segundo verso) en relaça paradigmatica com o messon 'a ilta du Marajó (cerceito verso). Nit estriste subsequicnte se repete a

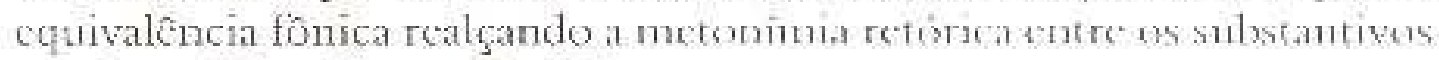
em rima 'Marajó' c carimbo:

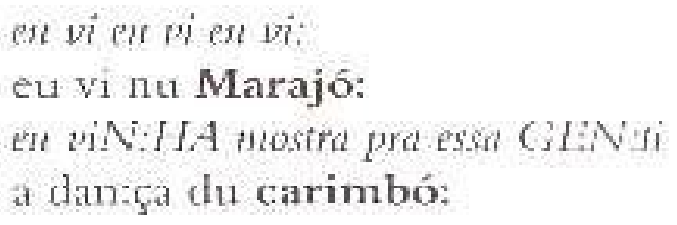

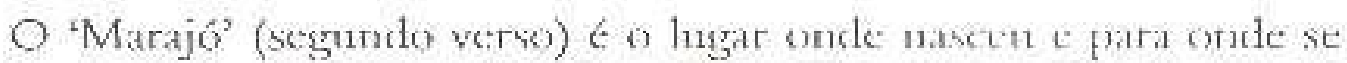
vai lcvar o 'carimbó' (quarto verso). Assim. as relacós scrâñticas são realcadas sonoramente nas duas estrofes demonstradas acima

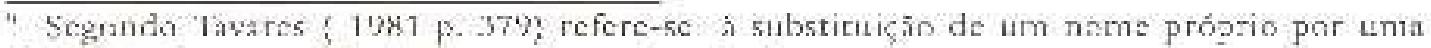

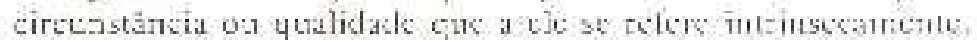




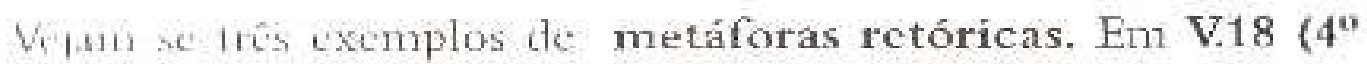
(-sirute):

\section{SO gata sasshimbia \\ SO onça matrikitijut}

En nato sem jaZI: SAN Nigri

Le engulo seimi misticat

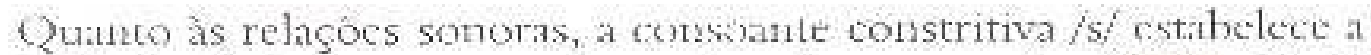
“quisalèn hia fônica entre os substantives 'sussuarana' e 'SANgui', O

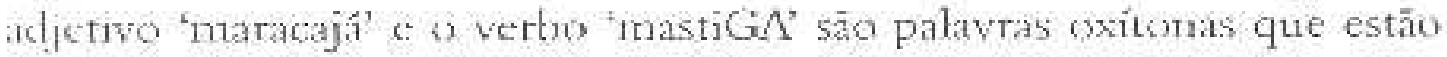
c11 tima.

Quanı às relaçóes semânticas, n€ primeiro par 'sussuarana', funciona como astjetivo referindo-sc à qualidade do atritad e 'SMNgui' retaciona-se ao efcito de uma açís do tnesmo ammal. No seggundo par, 'maracajá refete-se também à qualidacle do animal e 'mastiGA' rclaciona-sc ao etcito de nirra açno do animal. Assimn, a relaçāo semẩncica observada entre os pares de palavras que apresentam equivalencia sonora, nầ ș: mistra escreitr.

Se se atentar, porém, para as liguras retóricas (metíforas) construílas na estrofe, a mensagen ganhará maiuer realcé, $\Delta$ relação metafórica (retórica) cntre is "eu", representado pela forma verbal 'SO' e os substantivos dosignativos dos animais 'gaca' c 'onça' reforça a cquivalencia fônica observada entre as palavras finais dos vetsos.

As metaforas 'SO gata' e 'SO onça' sc reforchatr, apresentando-sc con similitude sintagrtrática. Vetifica-se a mesma estrutura sintagtrácica crutre os dois versos: verbo, substantivo L adjetivo. Assim, hat $11 т$ paralelismo sintácico por melo da semelhataga thite a estrutura das oraçōes simples nos duis pritneiros versos.

A forma verbal ' $\mathrm{SO}^{\prime}$ ' que introduy a tuctálora recórica assemel hasc sonorament: ao adjecivo (susssuarana) e : 0 sulsktatitivo (onça) que respectivamente cardcteriza e designa o animal. Também, a palavra 'sussuarana', que qualifica o animal expresso no primeiro verso (portanto particnlariza a palavra 'gata'), cstá em paralelo sonoro com o termo genérico 'onça', designactor dos animal expresso no segundo verso: $/ \mathrm{su} /, / \mathrm{sa} /$. Assim, o plano da expressāo, por meio da aliteração $\mathrm{em} / \mathrm{s} /$, reforça as estreitas relaçües semânticas cratrt as palavras desta estrole. 
Las V 05 ma primenta estrote essit:

\section{Moça bonita que tá na janela \\ Borboleta da asn amarela \\ Anorcla Anarela Anarda \\ Burboleta da asa amarela}

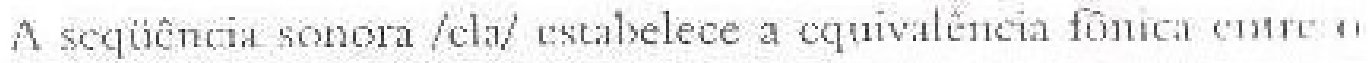

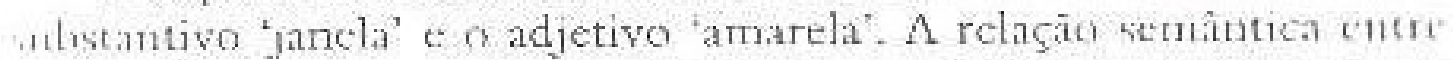

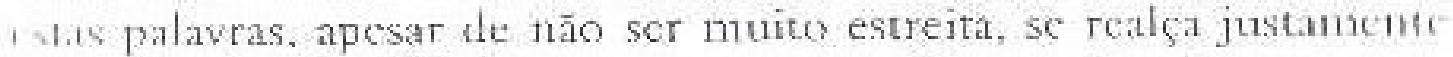
prot mcio da enincidência somora que constrôi untru outro signo, nu casu

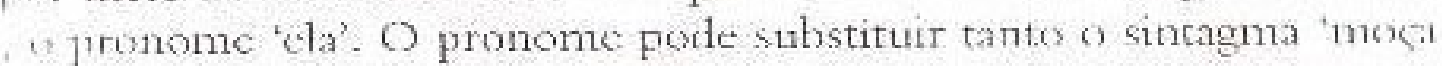
besmca' conno o substantivo 'borboleta'. A thorboleta' to sua beleza sik -1 inctáfora da 'moça bonica'. A figura retórica é marcada c: realçada m flimo da expressaño o pronome pessoal reso rediza isotopia cntre os dois sintagmas sobre os quais se constroi o processo metafórico. A mudade scinicit indicadora de ferninino prescrite taesce pronortie está prestitile en todas os subscantivos a adjetivos da estrofe.

Há outras equivalências fônicas que retorgarn a intima 'cumpulicidade' matre o plano da copressăo e o plano do contcudo. A oclusiva surda $/ \mathrm{h}$ seguida da vogal conrral $/ \mathrm{h} /$ faz a concxäo fonica c semântica entrc o aljecivo bonita", a a fornza verlacl tá' e o substantive 'borboleta'. Além desta relaçăo, a vogal /a/ se repetc em quase todas as palavias da cstrofi; aparecondo tatrobem nas palavras e silabas tiraus de todos os versos.

Considerandes a thetáfora cntre a 'moģa bontia e a borboleta?, se cstrçitarn as relaçous setnânticas entre as palavras 'jancla" e amarcla', A jatnela' e justamente o lugar em que a 'mos;i' fica exposta à lumitrosidade, a taridade do sol. () amarclo é a cor represcntariva da himinosidade ${ }^{j a}$.

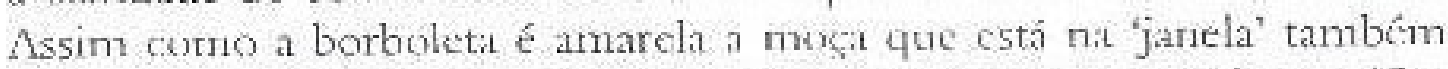
pode set comsiderada 'amarela', pois o sintą̧rna 'qui tá na jamelà significa expot-se à luminosidade, mostrat-se, atrair a melmuraçảo. A 'borboleta amarela' É a 'moça na jatıela' exposta aे lurnitzosidadc, à claridade do dia. $O$ plano da expressäo ć realçador ao mesmo tompurealça olano do conteúdo.

Em v.09 existem duas imagens que se constroem por meio de metátoras e metonimits:

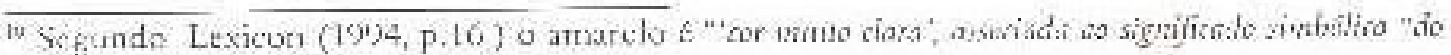
saro, da iks e th al:"
} 


\section{limoeik abaixi a rama \\ a QTiти liRA wim limău \\ su QLEñ tiRt uni mágua \\ que tein so men coraçău.}

A cquivalência fônica ć observada entre os substantivos 'rama' c

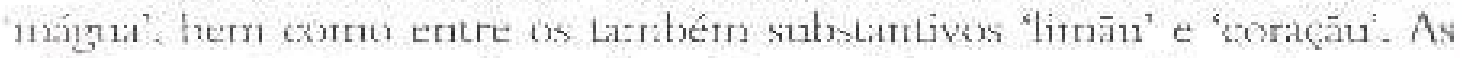
rehçōes senânticas mais estroitas nầ se dâo entre os substantivos que inelhor sc combinam sonoranentc. $O$ fato do 'limat' rinar com o 'coraçầ'

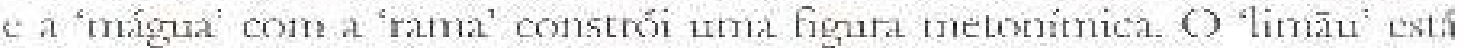

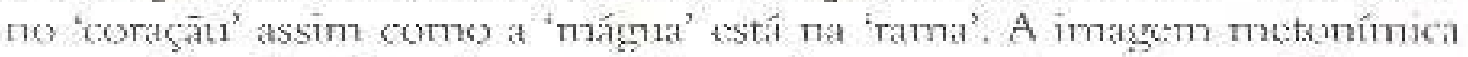
construída pelo plano da cxpressão conduz a uma imagem metafórica.

$A$ relaça metonímica observada inicialmente entre as palavras dos this pares ale: versos (entre os duis primeciros to os dois tiltimos) se: cunfirma no interior de cada dístico. O limāu' está na 'limocira' sonoramente (coincidència por treio da seqüência / linh') e setnanticatrente; também a "ramra está na limexira (por mocio (da sílaba $/ \mathrm{ra} /$ ) sonora s: serranticamente: A metonima é um processo intemo em cada dístico e a metáfora é un processo quil: miarca as relaçoes entres os dosis clísticos.

A metâtora sc constrói na relaço paradignática que se estabelece entre os dois dísticos: 'eu' sou a timoeira', a 'rafna' é o 'corachu' e o 'limàu (azcdo) é a 'máqua'. Entāo, assim como o 'limāu' está na 'rama' que escá na 'limoeira' a 'mágua' escá no 'coraçău que escá no 'eu'. As

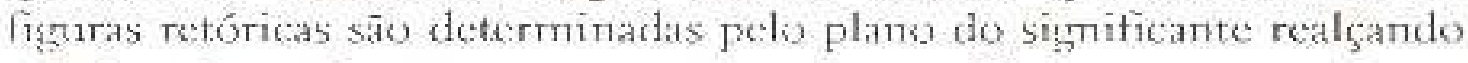
a uxtima interaçāo entré a expressão c a contcúdo.

Percencem ainda a esca categoria de textos: V.10 ( $2^{\circ}$ estrofe), V.17 ( $1^{\circ}$ e $3^{\circ}$ estrofe).

A partir dos textos analisados, verifica-se o predominioda funço poética thos textos de Verequete. Entre todas as vinte estrofes escudadas, encontramse cquivalencia fornica ente as palaveds firatis dos versis. Destas, sumente cm duas $(10 \%)$ a similitude sonora nāo comespondeu a uma estrcita relação scmântica entre as palavras. Encre as dezoito estrofes que combinam

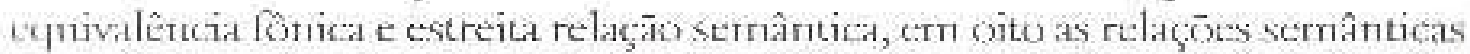
sitc de sinonimia tocal ou parcial. As dez restantes correspondem a figuras réúficas. Vale ressaltar que entre as correspondên wow sinominas, cerca de: trinta c: três por conto (33\%) nâo correspondem fealmeite a sinonímias, mas se verificam sinonimias parciais.

Eun cerca de noventa por cento $(90 \%)$ das estrotes se verificou a ecpunvalincia fontuca (rima ou assonânça)e a relaçâo semântica estreita 


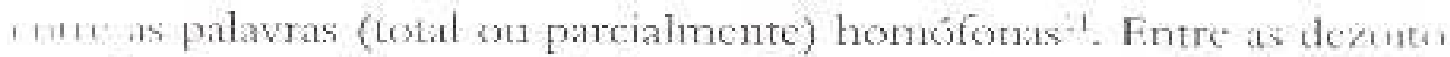

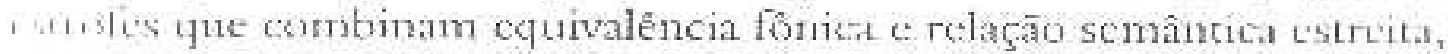
wow $\left(17^{60}\right)$ apresentam as relaçōes semânticas total su parcialntente monimas, dez $(53 \%)$ apresentam as relacóes retóricas (metonimus in inetutisras no sencido clássico)

En cinqüenta por cento $(50 \%)$ das csrrofes estudadas, há uma

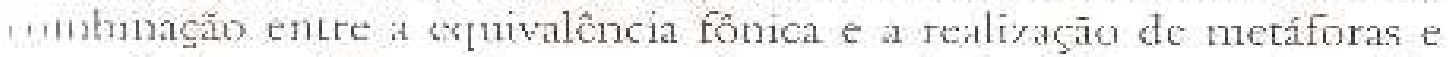

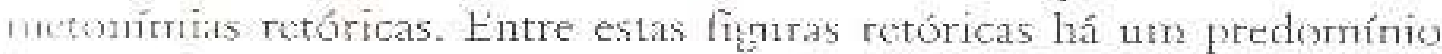
de incriftoras. Há um número bastante significativo de fimpras retóricas 11 is textos de Verequetc. Tncontrou-se um total de vinte tiguras zcróricas, who cincu ma tonímias e quatorze metáforas. Veritica-se uma proporç̄os d. stuase uma figura por estrofe: Tha cstrofes que apreseritam ate três liguras. Observan-se estrotis $\mathrm{cm}$ que se verifica, an mesmo tompo, liztáforas e tnetonimias, algumas destas construidas, a partir de un raliarç sonoro significativo para o estabelecimento da relacáo retórjca.

Analisararn-se as estrotes a partir de uma certa şradaçăo dos recursos expressivos (crfasc no significante). Trutä, as estrofes analisadis, primcipalmonte relativas ì duss últimas categorias de textos estudados (B. I e B.2), primam por uma estreita ituteraça cntre o plano da "xpressia c do conteúdo, realsando o processo melafórico, logso, a tunçâo poécica nos textos de Vercquete.

O fato de conscguir-se analisat as cstrofes de um mesino texto de: Vercqucte sepatadatmerse demonstra que hâ una certa inckpendència

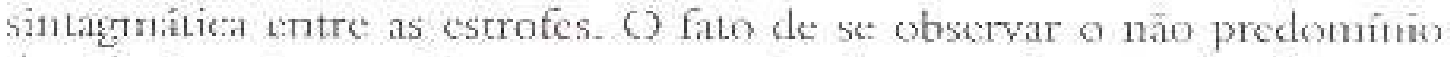
de relaçós sintagmáticas tu constriço das estrofes, năo signitica que: estas relaçöes estejann ansentes. Encontram-se nos textens th. Vercquete,

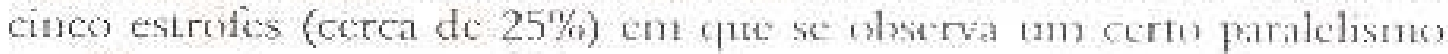
siorático entre os versos. Vestes casoss as estruturas sultitucas se 1130 tram

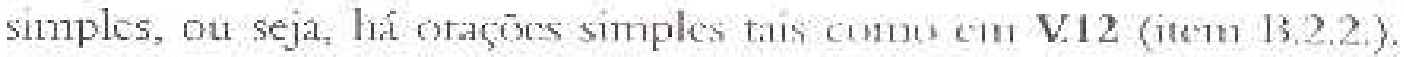

Na corstituiço dos textos de Verequete é bistante significativa a presença do processo metaforico A prependerincia do proxesso metaforico tuos textos deste compessiter resulta na maior predorninância da funçäo poética. Quatudo it funçio poctica predomina num texto, significa que a mensagem é cofacizada entes outros elementos do processo comunicativo. Tal enfase ć constatada nos textos de Vercquete, o que os aproxitnarn mais do gênero lírico.

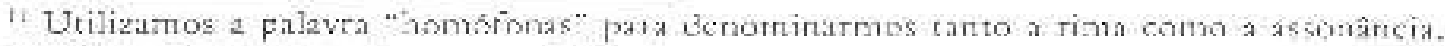
tamhém urilzateinos o tcrene cyuivalüncia sonora.
} 
A fuesta, representaliva do gencru líricos, se mostra corro um forte unficios textual da destinaçāe performática dos textos de Karequece. $\Lambda$ fusisia lírica temule a se realçar no canto.

\section{BIBLIOGRAFIA}

HIRITO, Mitra Leonora M. de. Lina leima in misicn de Waldemar Itemine. Belem: C.TJLP, 1986.

CLAVER FIITO o canto da Amazônia. Brasília: TINARTE, 1978.

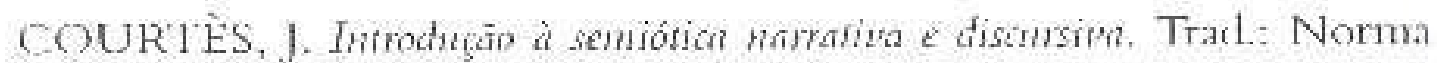
Backes Tisca. Combra: Ljuraria Alnedina, 1970.

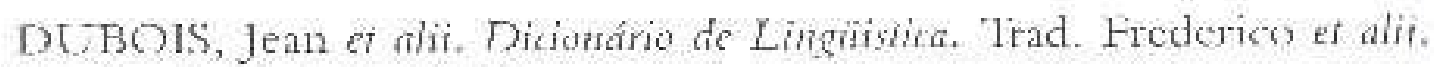
Sào Paulo: Conltix, 1997.

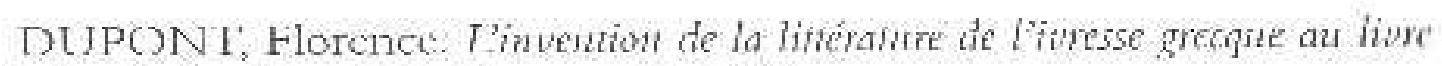
Intin. Paris: Ed. de la Deconverte, 1994.

tERRFIRA, Antélio Buarque de: I I. Novo diciomario da lingtia portuguesd. 2 ed. Rio de Janciro: Nesa Frontcira, 1986 ( $36^{2}$ impressāo).

GODINHO. Scbastiāo. Watemar Henrinue da Costa Peneim. Acréscida de song-book organizado pelo municista Yuri Gucdello. Belém, 1994.

JAKOBSON, Romar. I.ingüstica e comsnicaçāo. Trad. Isidoro Blikstein ¿ Joś́ Panlo Paes. 8 ad. Săn Paulo: Cultrix, 1988.

LEAI, Iniz Augusto I? As momposizues do Cimpun: experiencins do cotidiano expressa em letras do Conjusto de carimhó de Vereqnetc. Belém: Departanento dc. Ancropologia/CJTPA, 1998.

LEXICON, Herder. Dicionário de sínbolos. Trad.: Trelon: José P. São Paulo: Bib Cultrix, 1994.

PLNIAO, Francisco; HIORIN, José L. Para entender o sexto. Leitura e

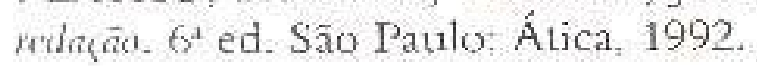

TAVARES, Tếtio Úlcimo da C. Teria literária. 8 ed, Belo Horizonte: Itatiatia, 1981. 